\title{
MANAJEMEN REKRUTMEN TENAGA PENDIDIK DI MADRASAH ALIYAH
}

\author{
Lisnandari \\ Madrasah Aliyah Al-Inaayah Garut \\ Jl. Raya Bungbulang Rt 06 Rw 02 Pakenjeng Garut \\ Email : lisnandari.me@gmail.com
}

\begin{abstract}
ABSTRAK
Proses rekrutmen merupakan hal yang sangat penting agar diperoleh hasil rekrutmen yang efektif. Rekrutmen yang dilakukan disesuaikan dengan kebutuhan sekolah. Penelitian ini bertujuan mengetahui manajemen rekrutmen tenaga pendidik di Madrasah Aliyah Al-Inaayah. Metode penelitian yang digunakan dalam penelitian ini ialah metode deskriptif kualitatif dengan teknik pengumpulan data yang dilakukan melalui wawancara, observasi, dan studi dokumentasi. Perencanaan yang matang yang dilakukan oleh panitia rekrutmen tenaga pendidik. Pelaksanaan rekrutmen tenaga pendidik yang dilaksanakan oleh panitia rekrutmen. Pengawasan yang efektif dan kondusif yang dilakukan oleh petugas pengawas rekrutmen tenaga pendidik. Evaluasi rekrutmen tenaga pendidik oleh ketua panitia rekrutmen dengan memeriksa kembali persyaratan peserta pelamar. Hasil dari proses rekrutmen secara kuantitatif: pencapaian rekrutmen yang dilaksanakan Madrasah Aliyah Al-Inaayah mencapai 23 tenaga pendidik, dan secara kualitatif: rekrutmen tenaga pendidik sesuai dengan kebutuhan Madrasah Aliyah Al-Inaayah; yaitu mendapatkan tenaga pendidik yang profesional.
\end{abstract}

Kata Kuci : Manajemen, Rekrutmen, Tenaga Pendidik.

\begin{abstract}
The recruitment process is very important in order to obtain effective recruitment results. Recruitment is carried out according to school needs. This study aims to determine the management of recruitment of educators in AlInaayah Aliyah Madrasas. The research method used in this study is a qualitative descriptive method with data collection techniques carried out through interviews, observation, and documentation studies. Careful planning carried out by the teaching staff recruitment committee. The recruitment of teaching staff carried out by the recruitment committee. Effective and conducive supervision carried out by officers who supervise the recruitment of educators. Evaluation of teaching staff recruitment by the chairman of the recruitment committee by re-examining the requirements of applicant participants. The results of the quantitative recruitment process: the achievement of recruitment carried out by Al-Inaayah Aliyah Madrasah reached 23 educators, and
\end{abstract}


qualitatively: recruitment of teaching staff according to the needs of Al-Inaayah Madrasah Aliyah; namely getting professional educators.

Keywords: Management, Recruitment, Educators.

\section{PENDAHULUAN}

Pendidikan yang dilaksanakan harus mampu menciptakan sumber daya manusia yang berkualitas baik pada tingkat lokal, nasional maupun internasional. Pendidikan diperlukan dan dipandang sebagai kebutuhan dasar bagi masyarakat yang ingin maju. Pendidikan memegang peranan yang amat penting untuk menjamin kelangsungan hidup negara dan bangsa, karena pendidikan merupakan wahana untuk meningkatkan dan mengembangkan kualitas sumber daya manusia (Siti Tsuwaibah 2010:1). Dalam meningkatkan mutu pendidikan sangat berkaitan erat dengan masalah Sumber Daya Manusia, karena dengan adanya Sumber Daya Manusia yang professional dapat meningkatkan mutu pendidikan yang lebih tinggi.

Salah satu kunci utama dalam menciptakan Sumber Daya Manusia (SDM) professional adalah terletak pada proses rekrutmen, seleksi, training and development calon tenaga kerja. Tentu saja rekrutmen yang dilakukan haruslah sesuai dengan kebutuhan sekolah yang ditentukan sekolah. Agar rekrutmen yang dilakukan tidak hanya sekedar mengisi kekosongan pegawai atau sekedar mendapatkan Sumber Daya Manusia (SDM) yang biasa saja. Tetapi Sumber Daya Manusia yang profesional di bidangnya sehingga dapat meningkatkan mutu pendidikan sekolah tersebut (Tsuwaibah 2010: 1).

Rekrutmen dapat didefinisikan sebagai sebuah proses mencari dan menarik (pembujuk untuk melamar) pelamar yang memenuhi syarat untuk mengisi jabatan/posisi tertentu yang lowong, yang telah diidentifikasi dalam perencanaan sumber daya manusia (Meldona, 2009:132).

Perekrutan adalah proses menarik orang-orang pada waktu yang tepat, dalam jumlah yang cukup, dan dengan persyaratan yang layak, untuk mengisi lowongan dalam organisasi, (R.Wayney Mondy, 2008:132).

Tenaga pendidik menurut Undang-undang No. 20 Tahun 2003 tentang sistem pendidikan Nasional pasal 39 ayat 2 pendidik merupakan tenaga profesional yang bertugas merencanakan dan melaksanakan proses pembelajaran, menilai hasil pembelajaran, melakukan bimbingan dan pelatihan, serta melakukan penelitian dan pengabdian kepada masyarakat, terutama bagi pendidik pada perguruan tinggi. Sumber daya manusia yang digunakan lembaga sangat tergantung pada bagaimana prosedur rekrutmen dilaksanakan, sebagaimana disebutkan di atas bahwa manajemen dalam pendidikan sangatlah penting bagi sebuah organisasi pendidikan.

\section{KAJIAN TEORI}

Manajemen berasal dari kata to manage yang artinya mengatur/mengelola. Manajemen adalah "ilmu dan seni yang mengatur proses pemanfaatan sumber daya manusia secara efektif yang didukung oleh sumbersumber lainnya dalam suatu organisasi untuk mencapai tujuan tertentu (Badrudin, 2013:1).

Menurut Terry (2015: 9-10) Manajemen adalah suatu bentuk kerja. Manajer, dalam melakukan pekerjaannya, harus melaksanakan kegiatan- 
kegiatan tertentu, yang dinamakan fungsi-fungsi manajemen, yang terdiri dari: (1) Planning, menentukkan tujuan-tujuan yang hendak di capai selama suatu masa yang akan datang dan apa yang harus diperbuat agar dapat mencapai tujuan-tujuan itu; (2) Organizing, mengelompokkan dan menentukkan berbagai kegiatan penting dan memberikan kekuasaan untuk melaksanakan kegiatan itu. (3) Staffing, menentukkan keperluan-keperluan sumber daya manusia, pengarahan, penyaringan, latihan, dan pengembangan tenaga kerja; (4) Motivating, mengarahkan atau menyalurkan perilaku manusia kearah tujuantujuan; (5) Controlling, mengukur pelaksanaan dengan tujuan-tujuan, menentukkan sebab-sebab penyimpangan-penyimpangan dan mengambil tindakan-tindakan korektif yang diperlukan.

Penarikan (rekrutmen) yaitu suatu proses yang dilakukan oleh organisasi. Untuk mendapatkan pegawai melalui beberapa tahapan mencakup evaluasi dan identifikasi penarikan tenaga kerja. Menentukan kebutuhan tenaga kerja, proses seleksi, penempatan, dan orientasi tenaga kerja (Malthis, 2010:43).

Menurut Bafadal (2008: 22), dalam rangka mendapatkan calon guru atau tenaga pendidik yang professional, harus memenuhi kualifikasi, dan menjanjikan untuk menduduki posisi tertentu tidaklah mudah. Ada beberapa prinsip yang harus dipegang teguh dalam perencanaan atau pelaksanaan rekrutmen guru, diantaranya: (1) Rekrutmen guru harus dirancang dan di rencanakan secara matang, agar dapat memenuhi kebutuhan untuk mendapatkan guru yang professional; (2) Rekrutmen guru baru harus dilakukan secara objektif. Artinya panitia seleksi pegawai guru baru menetapkan pelamar yang lulus dan pelamar yang tidak lulus secara objektif. (3) Agar mendapatkan calon yang professional, sebaiknya materi seleksi pegawai guru baru harus komprehensif mencakup semua aspek persyaratan yang harus dimiliki oleh calon guru.

Pada poreses rekrutmen tenaga pendidik diberlakukan beberapa alasan, hal ini berguna untuk meningkatkan kualitas sekolah. Adapun,alasan-alasan rekrutmen tenaga pendidik menurut Tsuwaibah (2010:33), adalah: (1) Berdirinya sekolah baru penambahannya kelas baru karena meningkatnya jumlah siswa, jadi membutuhkan guru baru; (2) Adanya kegiatan les atau ekstrakurikuler membutuhkan guru baru; (3) Terciptanya pekerjaan dan dengan adanya rancangan program baru sehingga membutuhkan guru baru pula; (4) Tenaga pendidik yang di mutasi dan pindah kesekolah lain membutuhkan guru baru; (5) Tenaga pendidik yang berhenti karena cuti hamil dan meninggal dunia membutuhkan guru baru; (6) Adanya pekerja yang berhenti karena memasuki usia pension, sudah tidak mungkin melakukan proses belajar mengajar.

\section{METODE PENELITIAN}

Penelitian ini digunakan pendekatan kualitatif. Sedangkan metode yang digunakan dalam penelitian ini ialah metode deskriptif kualitatif. Teknik pengumpulan data dilakukan ialah dengan teknik wawancara, observasi, dan studi dokumentasi. Analisis data digunakan unitisasi data, kategorisasi data, serta penafsiran data. Uji keabsahan data dilakukan dengan perpanjangan keikutsertaan, ketekukan pengamatan, triangulasi, pengecekan teman sejawat analisis kasus negatif, kecukupan referensi, uraian rinci, pengecekan anggota 
dan auditing. Uji absah data dilakukan untuk membuktikan bahwa data yang diterima merupakan data yang sebenarnya terdapat pada tempat penelitian.

\section{HASIL DAN PEMBAHASAN \\ Perencanaan Rekrutmen Tenaga Pendidik}

Perencanaan yang sangat matang yang disiapkan dalam melakukan perekrutan Tenaga Pendidik terlebih dahulu diadakan rapat tersebut dengan seluruh tenaga pendidik di Madrasah Aliyah Al-Inaayah. Rapat tersebut adalah untuk memilih panitia pelaksanaan rekrutmen tenaga pendidik. Agar tidak terjadi kesalahan dan kegagalan yang tidak diinginkan, diharapkan dengan adanya perencanaan yang matang dan jelas maka perekrutan dapat berjalan dengan lancar dan sesuai yang diinginkan yaitu mendapatkan tenaga pendidik yang baik, sesuai dengan kebutuhan yang dibutuhkan Madrasah.

Dalam persiapan pelaksanaan rekrutmen guru baru di Madrasah Aliyah Al-Inaayah meliputi berbagai kegiatan. Kegiatan persiapan rekrutmen guru baru meliputi: (1) Penyiapan fasilitas yang diperlukan dalam proses rekrutmen guru baru; (2) Penetapan persyaratan-persyaratan untuk melamar menjadi guru baru; (3) Penetapan prosedur pendaftaran guru baru; (4) Penyiapan ruang atau tempat memasukan lamaran guru baru. (5) Penyiapan pedoman pemeriksaan, hasil ujian dan tempat ujian rekrutmen.

Pembentukan panitia rekrutmen Tenaga Pendidik di MA Al-Inaayah dibentuk setelah kebutuhan guru jelas. Yang menentukan siapa saja yang menjadi panitia rekrutmen Tenaga Pendidik adalah kepala Madrasah Aliyah AlInaayah dan pengurus bagian personalia.

Penetapan jadwal yang dilaksanakan oleh panita yang bertaggung jawab disesuaikan dengan proses yang telah disiapkan Madrasah dengan demikian hal ini dapat berjalan dengan lancar sesuai yang di inginkan yakni efektif dan efisien dalam keberlangsungan program yang akan dilaksanakan. Jadwal ini harus didistribusikan kepada setiap pihak yang ikut dalam kegiatan dan harus dipastikan bahwa semua orang yang terlibat telah dikonfirmasikan untuk memastikan bahwa semua orang yang terlibat untuk dikonfirmasi memastikan waktunya sesuai dengan peserta atau panitia dapat hadir untuk melaksanakan kegitan tersebut.

Informasi lowongan pegawai baru/rekrutmen yang dilakukan oleh Madrasah Aliyah Al-Inaayah dapat diperoleh dari berbagai macam saluran. Hal ini dimaksudkan agar pelaksanaan rekrutmen berjalan secara efektif sesuai dengan potensi yang dibutuhkan.

Setelah pengumuman lowongan guru baru telah tersebar maka banyak masyarakat yang mengetahui bahwa ada lowongan pekerjaan di Madrasah Aliyah Al-Inaayah sebagaimana tercantum dalam pengumuman lowongan guru baru. Panitia mulai melakukan kegiatan yang meliputi: (1) Lamaran pekerjaan biasanya diterima langsung oleh satpam yang bertugas di depan gerbang Madrasah Aliyah Al-Inaayah kemudian satpam memberikan lamaran-lamaran tersebut kepada panitia rekrutmen; (2) Setelah lamaran masuk maka panitia mengecek semua kelengkapan yang harus disertakan bersama surat lamaran; (3) Setelah semua lamaran masuk kemudian dilanjutkan dengan kegiatan merekap semua pelamar dalam format rekapitulasi pelamar. 
Proses ujian seleksi tidak begitu dilakukan oleh pihak Madrasah, hasil keseluruhan seleksi dapat dilakukan dari hasil wawancara dan surat lamaran yang diberikan calon pelamar kepada lembaga pendidikan Madrasah Aliyah AlInaayah dari situlah pihak Madrasah mengetahui keseriusan calon tenaga pendidik yang melamar.

\section{Pelaksanaan Rekrutmen Tenaga Pendidik}

Program rekrutmen yang dilaksanakan di Madrasah Aliyah Al-Inaayah diserahkan sepenuhnya kepada Tim Rekrutmen. Proses yang telah dilaksanakan dalam merekrut Tenaga Pendidik baru, di Madrasah Aliyah AlInaayah selalu berkembang menyesuaikan kebutuhan dan selalu belajar dari pengalaman rekrutmen sebelumnya. Ini semua merupakan bentuk dari perkembangan sebuah lembaga pendidikan, di Madrasah Aliyah Al-Inaayah sangat mengutamakan analisis sesuai kebutuhan.

Prosedur Proses Pelaksanaan Rekrutmen Tenaga Pendidik Madrasah Aliyah Al-Inaayah dilakukan beberapa tahap yaitu: (1) Wawancara Saringan Pendahuluan; (2) Pengisian Formulir Lamaran; (3) Wawancara Kerja. (4) Tes Seleksi. Seleksi ini tidak menggunakan sistem gugur, melainkan dengan scoring, dalam tes seleksi terdiri dari empat hal yaitu: tes kemampuan mengajar (micro teaching), tes pengetahuan computer atau IT (informasi Tekologi), tes membaca Al-Qur'an dan wawancara Madrasah. Keempat tes seleksi ini akan diberikan nilai kemudian diakumulasikan.

\section{Pengawasan Pelaksanaan Rekrutmen Tenaga Pendidik}

Pengawasan yang dilakukan oleh panitia pengawas pelaksana Rekrutmen Tenaga Pendidik di Madrasah Aliyah Al-Inaayah sangat baik dan tugas pengawas tidak hanya sebatas tata tertib yang tertulis untuk itu pengawas ruang dilarang merokok, ngobrol dengan teman-teman sesama, pengawas memberi isyarat atau petunjuk jawaban dan memberi bantuan dalam hal apapun. Pengawas juga dengan telitinya memeriksa biodata peserta pada lembar jawaban agar terinput dengan baik.

\section{Evaluasi Rekrutmen Tenaga Pendidik}

Menurut Djaali dan Pudji (2008:1), evaluasi yaitu proses menilai sesuatu berdasarkan kriteria atau tujuan yang telah ditetapkan, yang selanjutnya diikuti dengan pengambilan keputusan atas obyek yang dievaluasi. Evaluasi di Madrasah Aliyah Al-Inaayah dilakukan oleh ketua panitia rekrutmen tenaga pendidik. Dalam evaluasi tersebut ketua panitia dan panitia rekrutmen mengecek kembali data pelamar dari mulai surat lamaran, daftar riwayat hidup, pas foto terbaru, foto copy kartu identitas (KTP), foto copy ijasah beserta transkrip nilai, foto copy sertifikat-sertifikat yang dimiliki, dan foto copy referensi/pengalaman kerja yang dimiliki. Panitia rekrutmen tenaga pendidik merekap kembali semua nama-nama pelamar dalam format rekapitulasi pelamar sekaligus menentukan siapa yang layak diterima sebagai guru baru di Madrasah Aliyah Al-Inaayah. Cukup banyak peserta pelamar rekrutmen tenaga pendidik Madrasah Aliyah Al-Inaayah hingga mencapai 10 orang peserta pelamar. Yang diterima hanya 3 orang peserta pelamar, karena peserta pelamar banyak yang tidak sesuai dengan latar belakang pendidikannya dan ada beberapa peserta yang tidak memenuhi persyaratan yang sudah di tentukan madrasah. 


\section{Hasil Rekrutmen Tenaga Pendidik}

Hasil penelitian studi pendahuluan yang dilakukan pada tanggal 8 Januari 2018 peneliti menemukan bahwa Madrasah Aliyah Al-Inaayah melakukan pengrekrutan tidak sesuai dengan kebutuhan Madrasah. Yaitu ada tenaga pendidik saudara Sindi Resmana, S.E. yang mengajar tidak sesuai dengan latar belakang pendidikannya. Selain itu ia memegang 3 mata pelajaran diantaranya pelajaran Matematika, Penjaskes, dan Teknologi Informasi Komunikasi, dan ada tenaga pendidik lainnya yang mengajar tidak sesuai dengan latar belakang pendidikannya yaitu saudari Susilawati, S.Pd. Latar belakang pendidikannya yaitu pendidikan Bahasa Inggris tetapi mengajar Bahasa Indonesia. Di Madarasah aliyah Al-Inaayah ada 2 tenaga pendidik yang mengajar tidak sesuai dengan latar belakang pendidikannya dan memegang 3 mata pelajaran yaitu Sindi Resmana, S.E. dan Susilawati, S.Pd. Namun berbeda dengan hasil penelitian pendahuluan, hasil penelitian lapangan yang dilakukan pada tanggal 20 Juni 2018 menunjukan bahwa Madrasah Aliyah AlInaayah sudah melalukan rekrutmen dengan baik yang dapat dilihat dari segi kuantitatif dan segi kualitatif.

Rekrutmen yang dilaksanakan Madrasah Aliyah Al-Inaayah menghasilkan 23 tenaga pendidik yang memiliki kompetensi yang profesional. Adapun tenaga pendidik yang profesional adalah mereka yang memiliki kompetensi pedagogik, kompetensi pedagogik, kompetensi kpribadian, kompetensi profesional.

Kompetensi pedagogik yaitu kemampuan guru dalam proses belajar mengajar yakni persiapan mengajar yang mencakup merancang dan melaksanakan skenario pembelajaran, memilih metode, media, serta evaluasi bagi anak didik agar tercapai tujuan pendidikan baik pada ranah kognitif, afektif, maupun psikomotorik siswa.

Berperan sebagai guru memerlukan kepribadian yang unik. Kepribadian ini meliputi kemampuan kepribadian yang mantap, stabil, dewasa, arif, dan berwibawa, menjadi teladan bagi peserta didik, dan berakhlak mulia. Seorang guru harus mempunyai peran ganda, peran tersebut diwujudkan sesuai dengan situasi dan kondisi yang dihadapi.

Kompetensi sosial terkait dengan kemampuan guru sebagai makhluk sosial dalam berinteraksi dengan orang lain, sebagai makhluk sosial guru berperilaku santun, mampu berkomunikasi dan berinteraksi dengan lingkungan secara efektif dan menarik mempunyai rasa empati terhadap orang lain.

Guru adalah satu faktor penting dalam penyelenggaraan pendidikan di sekolah. Oleh karena itu meningkatkan mutu pendidikan, berati juga meningkatkan mutu guru. Meningkatkan mutu guru bukan hanya dari segi kesejahteraannya, tetapi juga profesionalitasnya. Sebagai seorang profesional guru harus memiliki kompetensi keguruan yang cukup. Kompetensi keguruan itu tampak pada kemampuannya menerapkan sejumlah konsep, asas kerja sebagai guru, mampu mendemonstrasikan sejumlah strategi maupun pendekatan pengajaran yang menarik dan interaktif, disiplin, jujur dan konsisten.

Secara kualitatif, keberhasilan Rekrutmen Tenaga Pendidik adalah mendapatkan tenaga pendidik sesuai dengan kebutuhan Madrasah Aliyah AlInaayah. Dari sebagian tenaga pendidik ada yang sudah tersertifikasi, sehingga 
jumlah jam mengajarnya diwajibkan mencapai 24 jam dalam kurun waktu 1 minggu. Sedangkan guru yang direkrut tidak ada yang bersetatus PNS. Secara kualitas seluruh tenaga pendidik memiliki kompetensi profesional. Seluruh tenaga pendidik mengajar sesuai dengan latar belakang pendidikannya. Sehingga dalam kegitan belajar mengajar berjalan dengan lancar. Selain itu tenaga pendidik mengajar tidak terpaku hanya dari satu sumber buku saja melainkan mencari tambahan referensi sumber buku lainnya yang relevan. Dari keseluruhan rekrutmen dapat dilihat peserta didik yang menjadi acuan mengenai hasil keseluruhan aktivitas peserta didik dari nilai peserta didik yang bagus dan memuaskan karena peserta didik menerima pelajaran dari guru yang sesuai bidang mengajar.

Keberhasilan ini pun dapat dilihat dari prestasi alumni Madrasah Aliyah Al-Inaayah yang sebagian besar siswanya melanjutkan ke jenjang perguruan tinggi, diantaranya ke UPI Bandung, UIN Bandung, IPI Garut dan perguruan tinggi lainnya. Selain keberhasilan prestasi alumni dari siswanya pun ada misalnya dalam prestasi PASKIBRAKA tingkat provinsi, prestasi olahraga seperti Voli Ball tingkat Kabupaten, dan prestasi dalam pramuka.

\section{SIMPULAN}

Perencanaan yang matang dilakukan Madrasah Aliyah Al-Inaayah dalam melakukan perekrutan Tenaga Pendidik diharapkan dengan adanya perencanaan yang matang, dan jelas maka perekrutan dapat berjalan dengan lancar dan sesuai yang diinginkan yaitu mendapatkan tenaga pendidik yang baik, sesuai dengan kebutuhan Madrasah. Pelaksanaan program rekrutmen yang dilaksanakan di Madrasah Aliyah Al-Inaayah diserahkan sepenuhnya kepada Tim Rekrutmen. Proses yang telah dilaksanakan dalam merekrut tenaga pendidik baru di Madrasah Aliyah Al-Inaayah selalu berkembang menyesuaikan kebutuhan dan selalu belajar dari pengalaman rekrutmen sebelumnya. Merupakan bentuk dari perkembangan sebuah lembaga pendidikan, di Madrasah Aliyah Al-Inaayah sangat mengutamakan analisis sesuai kebutuhan. Pengawasan yang dilaksanakan dalam pelaksanaan rekrutmen tenaga pendidik sesuai dengan apa yang direncanakan.

Pengawas pelaksana rekrutmen sudah mematuhi tata tertib yang ditentukan. Adapun tata tertib yang diberlakukan adalah bahwa pengawas ruang dilarang merokok, mengobrol dengan teman-teman sesama, memberi isyarat atau petunjuk jawaban dan memberi bantuan dalam hal apapun ketika ujian sedang berlangsung maka dari itu pelaksanaan rekrutmen berjalan dengan lancar.

Evaluasi dilakukan ketua panitia Rekrutmen Tenaga Pendidik Madrasah Aliyah Al-Inaayah serta panitia lainnya. Dalam evaluasi ketua panitia dan panitia Rekrutmen Tenaga Pendidik mengecek kembali data pelamar.

Hasil Rekrutmen Tenaga Pendidik Madrasah Aliyah Al-Inaayah Depok Pakenjeng Garut. a. Segi Kuantitatif Pencapaian Rekrutmen yang dilaksanakan Madrasah Aliyah Al-Inaayah menghasilkan 23 tenaga pendidik yang memiliki kompetensi yang profesional. Adapun tenaga pendidik yang profesional adalah sebagai berikut: 1) Kompetensi pedagogik 2) Kompetensi kepribadian. 3) Kompetensi Sosial. 4) Kompetensi profesional. b. Segi Kualitatif di Madrasah Aliyah Al-Inaayah Keberhasilan Rekrutmen Tenaga Pendidik 
sesuai dengan kebutuhan yang dibutuhkan dan secara kualitas seluruh tenaga pendidik memiliki kompetensi profesional. Dari seluruh jumlah tenaga pendidik mengajar sesuai dengan latar belakang pendidikannya. Sehingga dalam kegitan belajar mengajar berjalan dengan lancar.

\section{REFERENSI}

Badrudin. (2013). Dasar - Dasar Manajemen, Bandung: Alfabeta

Bafadal. (2008). Manajemen Peningkatan Mutu Sekolah Dasar. Jakarta: Bumi Aksara.

Hasibuan Maluyu S.P. (2008) Manajemen Sumber Daya Manusia, Jakarta: Bumi Aksara

Malthis. (2010) Manajemen Sumber Daya Manusia, Jakarta: Edisi Pertama Salemba Empat.

Meldona. (2009) Manajemen Sumber Daya Manusia Perspektif Integratif. Malang: UIN Malang Press.

R.Wayney Mondy. (2008) Manajemen Sumber Daya Manusia. Jakarta: Erlangga.

Siti Tsuwaibah, (2010:1) Studi tentang Manajemen Rekrutmen Tenaga Pendidik Guru. Semarang: Ypi Al Khoiriyyah

Undang-undang RI nomor 14 tahun 2005 \& Peraturan Pemerintah RI nomor 74 tahun 2008 tentang guru dan dosen, Bandung : Citra Umbara, 2009. 